\title{
Impact of Alpha-Adrenergic Receptor Antagonists on outcomes in patients with heart failure. A post- hoc analysis using National Health Fund database
}

\section{Bartosz Symonides}

Medical University of Warsaw

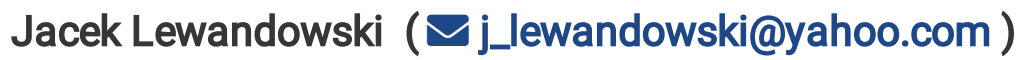

Medical University of Warsaw

Andrzej Śliwczyński

The National Health Fund

\section{Research Article}

Keywords: heart failure treatment, alpha-adrenolytics, mortality, readmissions

Posted Date: February 26th, 2021

DOl: https://doi.org/10.21203/rs.3.rs-259923/v1

License: (c) (i) This work is licensed under a Creative Commons Attribution 4.0 International License.

Read Full License 


\section{Abstract}

\section{Background}

The alpha-adrenolytics (AA) are not recommended in patients with EF reduced heart failure due to safety concerns. The aim of our study was to assess the safety of AA in patients hospitalized due to exacerbation of HF and the influence of these drugs on long-term endpoints.

\section{Methods}

Data collected by the National Health Fund was used. Patients hospitalized due to HF exacerbation were included. The primary outcome was all-cause mortality and the secondary was the first readmission due to $\mathrm{HF}$ or all-cause death occurring more than 30 days after discharge.

Results

Of 140668 patients hospitalized in the year $2013 n=53317$ were included and followed for a median of 56.3 months. AA patients had lower long-term mortality ( $52.8 \%$ vs. $54.9 \%$, unadjusted $P=0.038)$. The treatment with AA positively and affected long-term survival (adjHR $0.82,95 \% \mathrm{Cl} 0.78-0.87, \mathrm{P}<0.001$ ), as well as secondary endpoint (adjHR $0.85,95 \% \mathrm{Cl} 0.81-0.90, \mathrm{P}<0.001)$.

Cox analysis in the subgroup treated with beta-blockers revealed that treatment with AA was associated with lower mortality (adjHR $0.82,95 \% \mathrm{Cl} 0.75-0.90, \mathrm{P}<0.001$ ) and lower incidence of secondary endpoint (adjHR 0.85, 95\% Cl 0.78-0.92, P<0.001).

\section{Conclusions}

In compliant patients hospitalized due to HF exacerbation post discharge treatment with AA was safe and beneficial.

\section{Introduction}

The alpha-adrenolytics (AA) are currently not recommended in patients with EF reduced heart failure because of the safety concerns resulting from neurohormonal activation, fluid retention and exacerbating heart failure [1]. These drugs were also shifted to fourth line treatment of hypertension [2]. The above guidelines recommendations are primarily driven by the results of a well known ALLHAT (Antihypertensive and Lipid Lowering Treatment to Prevent Heart Attack Trial) trial that revealed the incidence of heart failure (HF) nearly doubled in doxazosin group compared with chlorthalidone group in patients treated for hypertension [3]. Some observational studies in elderly patients with hypertension also pointed to the at least double risk of development of HF related to the monotherapy with AA comparing thiazides $[4,5]$. 
However, newer observations revealed no harm related to the AA treatment in HF [6], and recently propensity-score analysis of a large cohort of one institution disclosed the reduction of mortality in $\mathrm{HF}$ with the AA treatment [7].

AA are the drugs used most commonly for male LUTS (lower urinary tract symptoms) treatment, disregarding whether or not related to benign prostatic enlargement (BPE) and are considered the first-line drug treatment for men with moderate-to-severe LUTS according to EAU guidelines [8]. In the crosssectional study of 122,630 elderly U.S. Medicare beneficiaries with HF BPE occurred in $6 \%$ of men [9].

Therefore the aim of our study was to assess the safety of AAs in patients hospitalized due to exacerbation of $\mathrm{HF}$ and the influence of these drugs on long-term all-cause mortality and combined endpoint consisting with mortality and readmissions due to exacerbations of HF in large database including the cases all-over the country.

\section{Results}

Of $n=140668$ patients who were hospitalized because of HF in the year $2013 n=53317$ were included in the final analysis. Figure 1 presents the flowchart of patient selection, Table 1 characteristics of all patients included to the final analysis.

Patients were followed for a median of 56.3 months (IQR 43.2 months).

Primary outcome (long-term all-cause mortality) occurred in $n=29226$ (54.8\%) and secondary outcome (combined long-term mortality with readmissions) in $n=34319(64.4 \%)$ in all patients. Group treated with non selective alpha-adrenolytics (AA) consisted of $n=2436$ of patients who were significantly older, and more frequently men as compared with $n=50881$ patients not treated with AA (nonAA group) (Table 1 ). Majority of the patients $(n=2409 ; 98.9 \%)$ were treated with doxazosin, the remaining with terazosin. Selective alpha blockers were used in a small number of all patients $n=1898(3.6 \%)$ with no significant difference between compared groups. 
Table 1

Characteristics of the total group

\begin{tabular}{|lllll|}
\hline & All patients & Without AA & AA & P \\
\hline $\mathrm{N}$ & 53317 & 50881 & 2436 & \\
\hline Age [yrs.] & $78.0(13.0)$ & $78.0(13.0)$ & $77.0(12.0)$ & 0.001 \\
\hline Females & $29766(55.8 \%)$ & $29236(57.5 \%)$ & $530(21.8 \%)$ & $<0.001$ \\
\hline Hospital stay [days] & $7.0(4.0)$ & $7.0(5.0)$ & $7.0(4.0)$ & 0.032 \\
\hline Advanced HF & $2455(4.60 \%)$ & $2344(4.61 \%)$ & $111(4.56 \%)$ & 0.947 \\
\hline RASI & $39507(74.1 \%)$ & $37619(73.9 \%)$ & $1888(77.5 \%)$ & $<0.001$ \\
\hline MRA & $23356(43.8 \%)$ & $22416(44.1 \%)$ & $940(38.6 \%)$ & $<0.001$ \\
\hline BB & $22023(41.3 \%)$ & $21024(41.3 \%)$ & $999(41.0 \%)$ & 0.777 \\
\hline Diuretics & $29550(55.4 \%)$ & $28102(55.2 \%)$ & $1448(59.4 \%)$ & $<0.001$ \\
\hline Digoxine & $7397(13.9 \%)$ & $7183(14.1 \%)$ & $214(8.78 \%)$ & $<0.001$ \\
\hline CCB & $9680(18.2 \%)$ & $8864(17.4 \%)$ & $816(33.5 \%)$ & $<0.001$ \\
\hline Nitrates & $5614(10.5 \%)$ & $5312(10.4 \%)$ & $302(12.4 \%)$ & 0.002 \\
\hline Antiplatelets & $1672(3.14 \%)$ & $1592(3.13 \%)$ & $80(3.28 \%)$ & 0.711 \\
\hline Anticoagulant & $9944(18.7 \%)$ & $9533(18.7 \%)$ & $411(16.9 \%)$ & 0.023 \\
\hline $\begin{array}{l}\text { Statins } \\
\text { Antidiabetics }\end{array}$ & $20706(38.8 \%)$ & $19564(38.5 \%)$ & $1142(46.9 \%)$ & $<0.001$ \\
\hline $\begin{array}{l}\text { BB - beta-blockers; AA - alpha-adrenolytics; RASI - renin angiotensin system inhibitors (converting } \\
\text { enzyme inhibitor and/or angiotensin receptor blocker); MRA - aldosterone receptor antagonists; CCB - }\end{array}$ & dihydropyridine calcium channel blockers. Data presented as numbers (percentages) or medians \\
\hline IQRs) & $13857(26.0 \%)$ & $12988(25.5 \%)$ & $869(35.7 \%)$ & $<0.001$ \\
\hline
\end{tabular}

The duration of hospital stay differed marginally, and the proportion of advanced HF was the same in both groups. The treatment assessed with filling the prescriptions differed between the groups with significantly higher use of ACEi/ARB, CCB, nitrates, statin, antidiabetic drugs and lower usage of MRA, diuretics, digoxine, anticoagulants in AA (Table 1). The proportion of patients treated with $\mathrm{BB}$ and antiplatelets (excluding ASA) was the same in both groups.

\section{Primary end-point}

AA patients had lower long-term all-cause mortality $(n=1285(52.8 \%)$ vs. $n=27941(54.9 \%), P=0.038$ for crude mortality). One year all-cause mortality was already lower in AA group ( $n=8381$ (16.5\%) vs. $n=340$ (14.0\%), $\mathrm{P}<0.001$ for crude mortality). 
All-cause mortality trends over time are presented in Fig. 2a with respective significant log-rank P values for the comparison of Kaplan-Meier curves. Cox analysis revealed that the treatment with AA positively and independently affected long-term survival (adjHR $0.82,95 \% \mathrm{Cl} 0.78-0.87, \mathrm{P}<0.001$ ). The analysis also disclosed age, gender, duration of hospitalization, and most of concomitant medications as independent covariants of long-term mortality (Fig. 3a).

\section{Secondary-end point}

Readmissions combined with mortality occurred less frequently in AA than in nonAA group $(\mathrm{n}=1527$ $(62.7 \%)$ vs $n=32792(64.4 \%), P=0.079$ for crude data).

The incidence of one year secondary-endpoint was lower in AA group $(n=11475$ (22.6\%) vs. $487(20.0 \%)$, $P=0.0039$ for crude data).

Secondary-endpoint trends over time are presented in Fig. $2 b$ with respective significant log-rank $P$ values for comparison of Kaplan-Meier curves. Cox analysis revealed that the treatment with AA positively and independently influenced secondary endpoint (adjHR $0.85,95 \% \mathrm{Cl} 0.81-0.90, \mathrm{P}<0.001$ ) with age, gender, duration of hospitalization, and most concomitant medications (Fig. 3B).

\section{Sub-analysis in BB treated patients}

Characteristics of a subgroup of patients who fulfilled prescription for BB was similar to that of the total group with lower ACEi/ARB use (Table 2). In contrast to the total group in the subgroup treated with BB no difference between $A A$ and nonAA groups were observed regarding $A C E i / A R B$, diuretic or anticoagulant treatment. 
Table 2

Characteristics of subgroup treated with beta blockers

\begin{tabular}{|lllll|}
\hline & All BB patients & BB without AA & BB with AA & P \\
\hline $\mathrm{N}$ & 22023 & 21024 & 999 & \\
\hline Age [yrs.] & $78.0(13.0)$ & $78.0(13.0)$ & $77.0(12.0)$ & 0.012 \\
\hline Females & $12031(54.6 \%)$ & $11834(56.3 \%)$ & $197(19.7 \%)$ & $<0.001$ \\
\hline Hospital stay [days] & $7.0(4.0)$ & $7.0(4.0)$ & $7.0(4.0)$ & 0.164 \\
\hline Advanced HF & $1083(4.92 \%)$ & $1029(4.89 \%)$ & $54(5.41 \%)$ & 0.513 \\
\hline RASI & $13645(62.0 \%)$ & $12999(61.8 \%)$ & $646(64.7 \%)$ & 0.077 \\
\hline MRA & $9203(41.8 \%)$ & $8835(42.0 \%)$ & $368(36.8 \%)$ & 0.001 \\
\hline Diuretics & $12877(58.5 \%)$ & $12275(58.4 \%)$ & $602(60.3 \%)$ & 0.253 \\
\hline Digoxine & $3442(15.6 \%)$ & $3342(15.9 \%)$ & $100(10.0 \%)$ & $<0.001$ \\
\hline CCB & $3671(16.7 \%)$ & $3340(15.9 \%)$ & $331(33.1 \%)$ & $<0.001$ \\
\hline Nitrates & $2587(11.7 \%)$ & $2442(11.6 \%)$ & $145(14.5 \%)$ & 0.006 \\
\hline Antiplatelets & $749(3.40 \%)$ & $718(3.42 \%)$ & $31(3.10 \%)$ & 0.658 \\
\hline Anticoagulant & $4355(19.8 \%)$ & $4169(19.8 \%)$ & $186(18.6 \%)$ & 0.369 \\
\hline $\begin{array}{l}\text { Statins } \\
\text { Antidiabetics }\end{array}$ & $8783(39.9 \%)$ & $8294(39.5 \%)$ & $489(48.9 \%)$ & $<0.001$ \\
\hline $\begin{array}{l}\text { BB - beta blockers; AA - alpha-adrenolytics; RASI - renin angiotensin system inhibitors (converting } \\
\text { enzyme inhibitor and/or angiotensin receptor blocker); MRA - aldosterone receptor antagonists; CCB - } \\
\text { dihydropyridine calcium channel blockers. Data presented as numbers (percentages) or medians } \\
\text { (IQRs) }\end{array}$ & $5903(26.8 \%)$ & & & \\
\hline
\end{tabular}

The most frequently used BB was carvedilol $(n=13022 ; 59.1 \%)$, followed by metoprolol $(n=3093 ; 14.0 \%)$, nebivolol $(n=2976 ; 13.5 \%)$, bisoprolol $(n=1153 ; 5.24 \%)$ and other, non HF approved BB $(n=1779 ; 8.08 \%)$.

Carvedilol was more frequently used in AA group compared with nonAA group $(\mathrm{n}=12494(59.4 \%)$ vs. $n=$ $528(52.9 \%) ; P<0.001)$ while non significant difference in non HF approved BB was seen between the groups.

Primary endpoint occurred less frequently in AA group compared with nonAA group ( $\mathrm{n}=553(55.4 \%)$ vs. $n$ $=12119$ (57.6\%), $\mathrm{P}=0.162$ for crude data) (Fig. 2c). Cox analysis revealed that difference as significant (adjHR $0.82,95 \% \mathrm{Cl} 0.75-0.90, \mathrm{P}<0.001$ ), with age, gender, and most concomitant medications as independent covariants (Fig. 4a). Secondary endpoint occurred less frequently in AA group comparing nonAA group ( $n=648(64.9 \%)$ vs. $n=14057(66.9 \%), p=0.202$ for crude data) (Fig. $2 d)$. Cox analysis 
revealed that difference as significant (adjHR 0.85, 95\% Cl 0.78-0.92, $\mathrm{P}<0.001$ ), with age, gender, and most concomitant medications as independent covariants (Fig. 4b).

\section{Sub-analysis in men only}

In a subgroup of men only characteristics of the patients and the differences between AA and non AA groups were generally similar to the all patients groups with some exceptions. In non AA comparing AA group advanced HF was present more frequently $(5.9 \%$ vs. $4.5 \%, P=0.023)$ and the usage of CCB higher $(13.2 \%$ vs. $27.5 \%, P<0.001)$ but there were no differences in duration of stay and diuretic use between groups (Table 3).

Table 3

Characteristics of the men only group

\begin{tabular}{|lllll|}
\hline & All men & Men without AA & Men on AA & P \\
\hline $\mathrm{N}$ & 23551 & 21645 & 1906 & \\
\hline Age [yrs.] & $74.0(16.0)$ & $74.0(17.0)$ & $77.0(12.0)$ & $<0.001$ \\
\hline Hospital stay [days] & $7.00(5.0)$ & $7.0(5.0)$ & $7.00(4.0)$ & 0.245 \\
\hline Advanced HF & $1341(5.69 \%)$ & $1255(5.80 \%)$ & $86(4.51 \%)$ & 0.023 \\
\hline RASI & $17046(72.4 \%)$ & $15599(72.1 \%)$ & $1447(75.9 \%)$ & $<0.001$ \\
\hline MRA & $10831(46.0 \%)$ & $10068(46.5 \%)$ & $763(40.0 \%)$ & $<0.001$ \\
\hline BB & $9992(42.4 \%)$ & $9190(42.5 \%)$ & $802(42.1 \%)$ & 0.766 \\
\hline Diuretics & $13377(56.8 \%)$ & $12257(56.6 \%)$ & $1120(58.8 \%)$ & 0.075 \\
\hline Digoxine & $3063(13.0 \%)$ & $2888(13.3 \%)$ & $175(9.18 \%)$ & $<0.001$ \\
\hline CCB & $3389(14.4 \%)$ & $2865(13.2 \%)$ & $524(27.5 \%)$ & $<0.001$ \\
\hline Nitrates & $2381(10.1 \%)$ & $2150(9.93 \%)$ & $231(12.1 \%)$ & 0.003 \\
\hline Antiplatelets & $899(3.82 \%)$ & $834(3.85 \%)$ & $65(3.41 \%)$ & 0.366 \\
\hline Anticoagulant & $4721(20.0 \%)$ & $4373(20.2 \%)$ & $348(18.3 \%)$ & 0.045 \\
\hline $\begin{array}{l}\text { Statins } \\
\text { Antidiabetics }\end{array}$ & $9523(40.4 \%)$ & $8635(39.9 \%)$ & $888(46.6 \%)$ & $<0.001$ \\
\hline $\begin{array}{l}\text { BB - beta-blockers; AA - alpha-adrenolytics; RASI - renin angiotensin system inhibitors (converting } \\
\text { enzyme inhibitor and/or angiotensin receptor blocker); MRA - aldosterone receptor antagonists; CCB - } \\
\text { dihydropyridine calcium channel blockers. Data presented as numbers (percentages) or medians } \\
\text { (IQRs) }\end{array}$ & $5861(24.9 \%)$ & & & \\
\hline
\end{tabular}


In this sub-analysis both primary and secondary endpoints occurred less frequently in AA group as compared to the nonAA group $(n=1047(54.9 \%)$ vs. $n=12444(57.5 \%), P=0.032$ for crude data) and $(n=$ $1232(64.6 \%)$ vs. $14448(66.7 \%), P=0.065$ for crude data) respectively (Supplementary Fig. S1 online). Cox analysis for primary and secondary endpoints revealed that both differences were significant (respectively: adjHR $0.82,95 \% \mathrm{Cl} 0.77-0.88, \mathrm{P}<0.001$ and adjHR $0.85,95 \% \mathrm{Cl} 0.80-0.90, \mathrm{P}<0.001$ ). Age, advanced $\mathrm{HF}$, and most concomitant medications were independent covariants for both endpoints (Supplementary Fig. S2 online).

\section{Discussion}

The results of our study revealed that in patients hospitalized all over the country in the year 2013 due to exacerbation of HF those additionally treated with AA had $18 \%$ lower risk of all-cause death mortality and $15 \%$ lower risk of secondary endpoint (mortality or readmission) compared to the patients not treated with AA.

Compared to classic registry data, the patients in our study were 5 to 9 years older [10-17].

Balsam et al. analysed $n=1415$ hospitalized patients from Polish cohorts of both ESC-HF Pilot and ESCHF-LT registries [17]. The mean age was lower (69 yrs.) than in our cohort. Hypertension was diagnosed in $68.9 \%, \mathrm{CAD}$ in $43.6 \%$, AF in $43.6 \%$ pts, diabetes in $35.1 \%$, CKD $20.9 \%$, COPD $18.8 \%$ of patients. In the large american ADHERE registry the most common comorbid conditions were hypertension (73\%), coronary artery disease (57\%), and diabetes (44\%) [13].

Despite the fact that only patients who purchased at least one of the classic drugs increasing survival were eligible for the study, in our cohort a lesser percentage of patients filled prescriptions for CV drugs comparing treatment at discharge in mentioned above Polish cohorts of European registries. While the difference regarding ACEi and ARB was approximately $10 \%$, and for MRA approx $20 \%$, in case of BB, diuretics, digoxine, statins the percentage was twice smaller [17].

These differences may reflect the poor compliance and filling prescriptions among real-life HF patients.

Probably some drugs were not prescribed at the time of discharge from hospital, possibly due to contraindications (hypotension, bradycardia, renal failure).

Our cohort represents real life data and included exclusively patients with exacerbation of HF in contrast to registry studies that also included stable and outpatient HF patients and were conducted most often by selected centers of the tertiary level, often academic so probably selecting patients with lower age, smaller number of concomitant diseases and with better compliance.

The percentage of AA use in our men-only subgroup (8\%) was similar to the frequency of BPE reported among U.S. Medicare beneficiaries with HF (6\%) [9] suggesting that treatment of BPE not hypertension was the main indication for AA treatment. 
Of $n=107229$ patients who were hospitalized for exacerbation of HF in the year 2013 but without hospital HF diagnosis in the previous year $10.3 \%$ patients died during the index hospitalization and $4.9 \%$ within 30 days after discharge, $4.3 \%$ were readmitted within 30 days. The in-hospital mortality was $2-3$ times higher than in registry studies [11], 13, 17].

Similarly to other registers that included acute HF patients, there was a high long-term mortality despite the fact that we excluded patients who died or were readmitted early $[18,19]$. Also one-year mortality was $50 \%$ higher than reported in Polish cohorts of European registries [17].

On the other hand, patients who were not hospitalized with the diagnosis of heart failure during the previous year and who purchased at least one drug reducing the risk of death in HF within 30 days were enrolled, so the study group probably included more patients with de novo heart failure and cooperating well.

We decided to combine readmissions with total mortality as a secondary endpoint, since we have data on readmissions due to exacerbation of HF only but not total cardiovascular hospitalizations. Moreover high mortality in our cohort interferes with assessment of other endpoints.

Unlike randomized drug trials conducted in HF, our group was not selected in terms of HF severity, NYHA class, EF, etiology, renal function and other clinical parameters. Most of the randomized trials in HF have ruled out multiple coexisting chronic diseases, so the populations studied do not reflect well the patients treated in the hospital for worsening heart failure. The real-word data differs from randomised controlled trials (RCT) because of frequent exclusion of concomitant chronic conditions. In one analysis $83 \%$ of RCT for heart failure excluded at least one chronic condition including $C H D$, hypertension, stroke, $A F$, COPD, depression or dementia [20].

The results of our study stays in contrast to the results of the ALLHAT study that disclosed nearly double the incidence of heart failure compared with chlorthalidone group in high risk hypertensive patients [3]. Although many authors explained the results of ALLHAT in doxazosin arm by the effect of neurohormonal activation from unopposed alpha receptor antagonism [21], others pointed to numerous limitations of the trial and issues needed to be addressed [22]. Systolic blood pressure was about $3 \mathrm{~mm}$ $\mathrm{Hg}$ higher in the doxazosin arm and increased incidence of heart failure in the doxazosin group was not accompanied by parallel increase in mortality. Moreover, the heart failure end point in ALLHAT was much higher than that observed in other trials of similarly high-risk patients and the curves for heart failure incidence in the doxazosin and chlorthalidone groups separated within weeks after randomization with little further separation thereafter. Therefore the treatment with doxazosin may rather have unmasked occult heart failure while diuretic treatment would have been more likely to maintain control of signs and symptoms of preexisting heart failure [22].

The results of the Matsui et al. study assessing the benefits of adding bed-time dose of doxazosin for controlling morning blood pressure and the left ventricular structure and function in hypertensive patients were unequivocal [23]. 
In the doxazosin group, an increase in the left ventricular diameter was only seen in patients who did not take diuretics throughout the study. Authors conclude that the prior use of diuretics can prevent the unfavorable effects of doxazosin on the left ventricular structure. These observations can explain the results of early studies with AA in HF.

On the other hand in a classical study comparing monotherapy with various 5 drugs in hypertensive men in the prazosin group there was no excess of oedema during more than one year follow-up, although the drug had also the highest rate of adverse effects leading to the termination of treatment [24].

In non-randomised analysis in the Anglo-Scandinavian Cardiac Outcomes Trial-Blood Pressure Lowering Arm (ASCOT-BPLA) that included almost 40000 patient-years the addition of doxazosin to the hypertensive treatment resulted in BP lovering by approximately $12 / 7 \mathrm{mmHg}$ with achieving target BP in one third of participants with no apparent excess of heart failure [25].

The observations regarding the use of AA in hypertnesive patients may not necessarily reflect well the use of these drugs in already treated HF.

In historical double blind comparison of captopril and prazosin in HF despite the maintained vasodilatation half of the 16 patients deteriorated after one month [26]. In our study, patients took (bought) at least one drug reducing mortality in heart failure. The study therefore tested the differences between adding AA as an additional drug to current therapy for heart failure, and did not compare AA with other classic drugs used in the treatment of HF.

The use of AA in a patient with HF in a situation where the drug is used to inhibit sympathetic activity and/or the RA system may not lead to excessive neurohormonal activation. The V-HeFT I trial revealed no differences in all-cause hospitalization between patients randomized to prazosin or hydralazine with isosorbide dinitrate or placebo in HF patients on background therapy of digitalis and diuretics [27].

The results of our study appear similar to the Jackevicius et al. study [7]. The authors performed the propensity score analysis of HF hospitalized in one institution from the year 2002 to 2015. Of 169911 patients who were hospitalized in the period of interest $28 \%$ were on AA. The authors matched 35715 pairs according to the AA treatment status using numerous covariants unfortunately with the exception of the most important as SBP and EF. The mean age of the matched group was lower ( $75 \mathrm{yrs}$ ) than in our study, and the usage of analysed drugs was higher than in our group with the exception of ACEi or ARB which was similar and MRA which was higher in our group. The treatment with AA was associated with lower 2-year all-cause mortality in the whole group (42.8\% versus $46.5 \%$ (HR: $0.93 ; 95 \%$ Cl: 0.91 to $0.94 ; \mathrm{P}$ $<0.0001)$ and also in BB treated group (HR: 0.91; $95 \%$ Cl: 0.89 to 0.92; $\mathrm{P}<0.0001)$. Higher doses and nonselective AAs were also associated with lower mortality, regardless of BB treatment. These secondary analyses were performed in a very similar way, as the our. Authors conclude that AAs may be used safely in HF patients where clinically indicated. 
Another example suggesting the benefits of adding AA to the treatment of HF is the COMET study (Carvedilol Or Metoprolol European Trial), that revealed a significant reduction in total and cardiovascular mortality with carvedilol compared with metoprolol [28].

Our study presents the typical limitations of a retrospective analysis of reimbursement data. However, the data were collected systematically and prospectively by a single insurer all over the country. Due to the limitations of the NHF database we were unable to assess many other important clinical parameters such as blood pressure, ejection fraction, laboratory tests (BNP or NTproBNP, plasma creatinine, natremia, haemoglobin) and concomitant diseases.

However we had data on duration of hospitalization, advanced HF (requiring treatment with positive inotropes or renal replacement therapy) and post discharge treatment. We assume that including these covariants into analysis partially substitutes controlling on important clinical parameters or concomitant diseases. Some of the studies mentioned in the above discussion also did not control results on crucial data such as SBP or EF due to incompleteness [7].

One can assume that the main indication for AA treatment in men was LUTS while in women poorly controlled hypertension. Therefore the men and women in our cohort may differ regarding both etiology and severity of HF. However the subgroup analysis in men only reflected the trends observed in the entire patient group.

Autopsies are rarely performed in Poland and a majority of deaths took place outside hospitals therefore we were unable to establish the cause of death.

A risk of potential errors or underreporting of diagnoses or procedures should also be taken into consideration.

Our all-over the country cohort analysis based on real world data revealed that in selected patients hospitalized due to HF exacerbation post discharge treatment with AA may be safe and beneficial. Since the inclusion/exclusion criteria we used the results of the study applied rather to the compliant patients without the highest risk of early post-discharge death or early readmission. The role of AA in HF warrants further research.

\section{Methods}

We used data collected by the National Health Fund (NHF), the only public and obligatory health insurer in Poland. The NHF is practically the single payer that signs contracts with public and private healthcare providers.

The NHF database tracks all patient admissions, main diagnoses and taking of the drug prescriptions longitudinally throughout the entire country. The database also includes birth and death dates. The database search included the period from Jan 1st 2012 to December 31st 2018. 
Inclusion criteria were patients who were hospitalized with International Classification of Diseases Tenth Revision (ICD-10) diagnosis code of 150 (congestive heart failure) due to HF exacerbation (specific NHF codes) in the 2013 year. We excluded patients who were hospitalized with the ICD-10 code I50 in the previous year disregarding the main reason for the hospitalization as well as the patients who died during and within 30 days after the index hospitalization. We also excluded patients who had not bought any prescribed HF drugs including angiotensin converting enzyme inhibitors (ACEi), angiotensin receptor blockers (ARB), aldosterone receptor antagonists (MRA) or beta-blockers (BB) within period of 30 days after the index hospitalizations. The earliest procedure was considered the index one.

The primary outcome variable was all-cause mortality and the secondary was the first readmission due to $\mathrm{HF}$ or all-cause death occurring more than 30 days after discharge.

Survival analysis was performed for primary and secondary outcomes adjusting for age, sex, duration of the index hospitalizations, severe HF as reported to NFH (defined as need for vasopressors or dialysis), taking the prescription for the selected drugs during 30 day period following the discharge. Following medication was included into the analysis: AA, ACEi and/or ARB, MRA, BB, any diuretic, digoxine, dihydropyridine calcium channel blocker (CCB), nitrates, antiplatelets other than acetylsalicylic acid (ASA), anticoagulants (vitamin K (VKA) or non-vitamin $\mathrm{K}$ antagonist oral anticoagulant (NOAC)), statins, antidiabetics. All-cause mortality outcomes were censored at the end of the study on December 31st 2018. All data released from NHF were fully anonymized by applying encrypted personal identifiers before the authors had any access to them.

\section{Statistics}

Variables were compared using Fisher's exact test and Mann-Whitney $U$ test. Estimates of cumulative event rates were calculated by means of the Kaplan-Meier method with the log-rank comparison of survival curves. Cox proportional-hazards analyses were performed for primary and secondary outcomes. The covariants for the models were selected using criteria of $\mathrm{P}<0.1$ in univariate analysis among above mentioned variables. Two additional subanalyses were also performed by repeating the calculations in 2 subgroups: in men only and in patients who received BB.

In BB subanalysis treatment with carvedilol (or not) and treatment with HF approved BB (carvedilol, metoprolol, bisoprolol or nebivolol) were additionally analysed.

$P$ values of less than 0.05 were considered significant. The statistical analysis of the data was performed using R (R version 3.6.1, R-core Team, R Foundation for Statistical Computing, Vienna, Austria, 2019, https://www.r-project.org), graphs with "survminer" and 'forestmodel" R packages.

One of the authors (BS) had full access to all the data in the study and takes responsibility for its integrity and the data analysis.

\section{Declarations}




\section{Author contributions}

B.S. and J.L. wrote the main manuscript. B.S. and A.S. were responsible for acquisition, analysis and interpretation of the data. All authors reviewed the manuscript.

\section{Competing interests}

The authors declare no competing interests.

\section{Data availability}

Available as Supplementary Information (Dataset.csv)

\section{Ethics declarations}

The study was not considered for review by the local ethical committee since the database was previously collected by a government agency and all data were fully anonymized, and fully encrypted before the authors had any access to them. Moreover, there was no direct patient contact whatsoever.

\section{References}

1. Ponikowski, P. et al. 2016 ESC Guidelines for the diagnosis and treatment of acute and chronic heart failure: The Task Force for the diagnosis and treatment of acute and chronic heart failure of the European Society of Cardiology (ESC)Developed with the special contribution of the Heart Failure Association (HFA) of the ESC. Eur. Heart J.37, 2129-2200 (2016).

2. Williams, B. et al. 2018 ESC/ESH Guidelines for the management of arterial hypertension. Eur. Heart J.39, 3021-3104 (2018).

3. ALLHAT Officers and Coordinators for the ALLHAT Collaborative Research Group. Diuretic versus alpha-blocker as first-step antihypertensive therapy: final results from the Antihypertensive and LipidLowering Treatment to Prevent Heart Attack Trial (ALLHAT). Hypertension.42, 239-246 (2003).

4. Bryson, C. L. et al. Risk of congestive heart failure in an elderly population treated with peripheral alpha-1 antagonists. J Am Geriatr Soc.52, 1648-1654 (2004).

5. Aronow, W. S. \& Ahn, C. Incidence of new coronary events in older persons with prior myocardial infarction and systemic hypertension treated with beta blockers, angiotensin-converting enzyme inhibitors, diuretics, calcium antagonists, and alpha blockers. Am. J. Cardiol.89, 1207-1209 (2002).

6. Dhaliwal, A. S. et al. Impact of alpha 1-adrenergic antagonist use for benign prostatic hypertrophy on outcomes in patients with heart failure. Am. J. Cardiol.104, 270-275 (2009). 
7. Jackevicius, C. A., Ghaznavi, Z., Lu, L. \& Warner, A. L. Safety of Alpha-Adrenergic Receptor Antagonists in Heart Failure. JACC Heart Fail.6, 917-925 (2018).

8. Abreu-Mendes, P., Silva, J. \& Cruz, F. Pharmacology of the lower urinary tract: update on LUTS treatment. Ther Adv Urol.12, 1756287220922425 (2020).

9. Braunstein, J. B. et al. Noncardiac comorbidity increases preventable hospitalizations and mortality among Medicare beneficiaries with chronic heart failure. J Am Coll Cardiol.42, 1226-1233 (2003).

10. O'Connor, C. M., Stough, W. G., Gallup, D. S., Hasselblad, V. \& Gheorghiade, M. Demographics, clinical characteristics, and outcomes of patients hospitalized for decompensated heart failure: observations from the IMPACT-HF registry. J Card Fail.11, 200-205 (2005).

11. Fonarow, G. C. et al. Influence of a performance-improvement initiative on quality of care for patients hospitalized with heart failure: results of the Organized Program to Initiate Lifesaving Treatment in Hospitalized Patients With Heart Failure (OPTIMIZE-HF). Arch Intern Med.167, 1493-1502 (2007).

12. Sato, N. et al. Acute decompensated heart failure syndromes (ATTEND) registry. A prospective observational multicenter cohort study: rationale, design, and preliminary data. Am Heart J.159, 949-9551 (2010).

13. Adams, K. F. et al. Characteristics and outcomes of patients hospitalized for heart failure in the United States: rationale, design, and preliminary observations from the first 100,000 cases in the Acute Decompensated Heart Failure National Registry (ADHERE). Am Heart J.149, 209-216 (2005).

14. Maggioni, A. P. et al. EURObservational Research Programme: the Heart Failure Pilot Survey (ESC-HF Pilot). Eur. J. Heart Fail.12, 1076-1084 (2010).

15. Maggioni, A. P. et al. EURObservational Research Programme: regional differences and 1-year followup results of the Heart Failure Pilot Survey (ESC-HF Pilot). Eur. J. Heart Fail.15, 808-817 (2013).

16. Chioncel, 0 . et al. Clinical phenotypes and outcome of patients hospitalized for acute heart failure: the ESC Heart Failure Long-Term Registry. Eur J Heart Fail.19, 1242-1254 (2017).

17. Balsam, P. et al. Differences in clinical characteristics and 1-year outcomes of hospitalized patients with heart failure in ESC-HF Pilot and ESC-HF-LT registries. Polish Archives of Internal Medicine.129, 106-116 (2019).

18. Lassus, J. P. E. et al. Long-term survival after hospitalization for acute heart failure-differences in prognosis of acutely decompensated chronic and new-onset acute heart failure. Int J Cardiol.168, 458-462 (2013).

19. Younis, A. et al. Differences in Mortality of New-Onset (De-Novo) Acute Heart Failure Versus Acute Decompensated Chronic Heart Failure. Am J Cardiol.124, 554-559 (2019).

20. Buffel du Vaure, C., Dechartres, A., Battin, C., Ravaud, P. \& Boutron, I. Exclusion of patients with concomitant chronic conditions in ongoing randomised controlled trials targeting 10 common chronic conditions and registered at ClinicalTrials.gov: a systematic review of registration details. BMJ Open.6, e012265 (2016).

21. Messerli, F. H. Implications of discontinuation of doxazosin arm of ALLHAT. Antihypertensive and Lipid-Lowering Treatment to Prevent Heart Attack Trial. Lancet.355, 863-864 (2000). 
22. Poulter, N. \& Williams, B. Doxazosin for the management of hypertension: implications of the findings of the ALLHAT trial. Am J Hypertens.14, 1170-1172 (2001).

23. Matsui, Y. et al. Effect of doxazosin on the left ventricular structure and function in morning hypertensive patients: the Japan Morning Surge 1 study. J. Hypertens.26, 1463-1471 (2008).

24. Materson, B. J. et al. Single-drug therapy for hypertension in men. A comparison of six antihypertensive agents with placebo. The Department of Veterans Affairs Cooperative Study Group on Antihypertensive Agents. N. Engl. J. Med.328, 914-921 (1993).

25. Chapman, N. et al. Effect of doxazosin gastrointestinal therapeutic system as third-line antihypertensive therapy on blood pressure and lipids in the Anglo-Scandinavian Cardiac Outcomes Trial. Circulation.118, 42-48 (2008).

26. Bayliss, J. et al. Clinical importance of the renin-angiotensin system in chronic heart failure: double blind comparison of captopril and prazosin. Br Med J (Clin Res Ed).290, 1861-1865 (1985).

27. Loeb, H. S. et al. Effect of enalapril, hydralazine plus isosorbide dinitrate, and prazosin on hospitalization in patients with chronic congestive heart failure. The V-HeFT VA Cooperative Studies Group. Circulation.87, VI78-87 (1993).

28. Poole-Wilson, P. A. et al. Comparison of carvedilol and metoprolol on clinical outcomes in patients with chronic heart failure in the Carvedilol Or Metoprolol European Trial (COMET): randomised controlled trial. Lancet.362, 7-13 (2003).

\section{Figures}




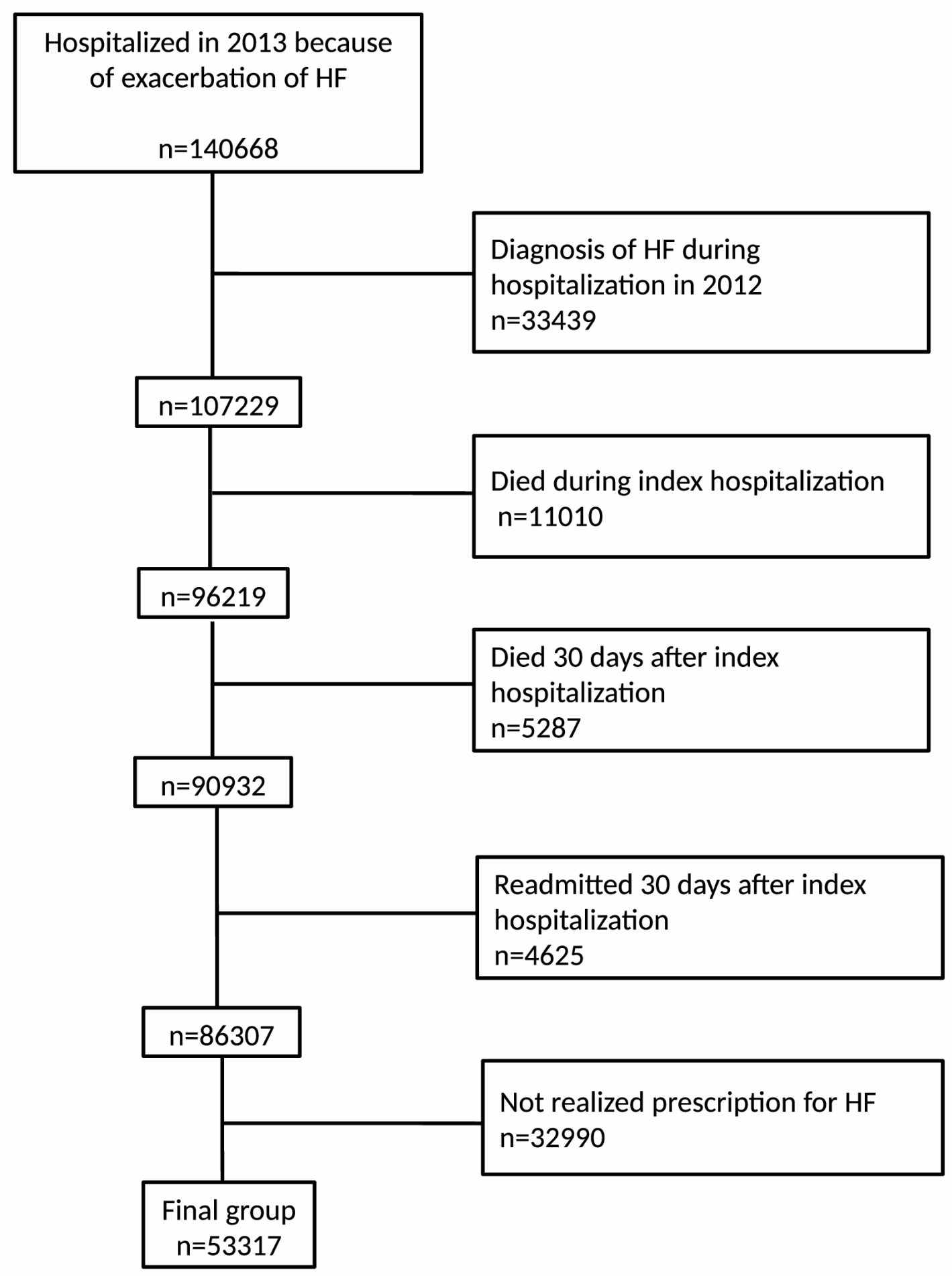

Figure 1

The flowchart of patient selection 


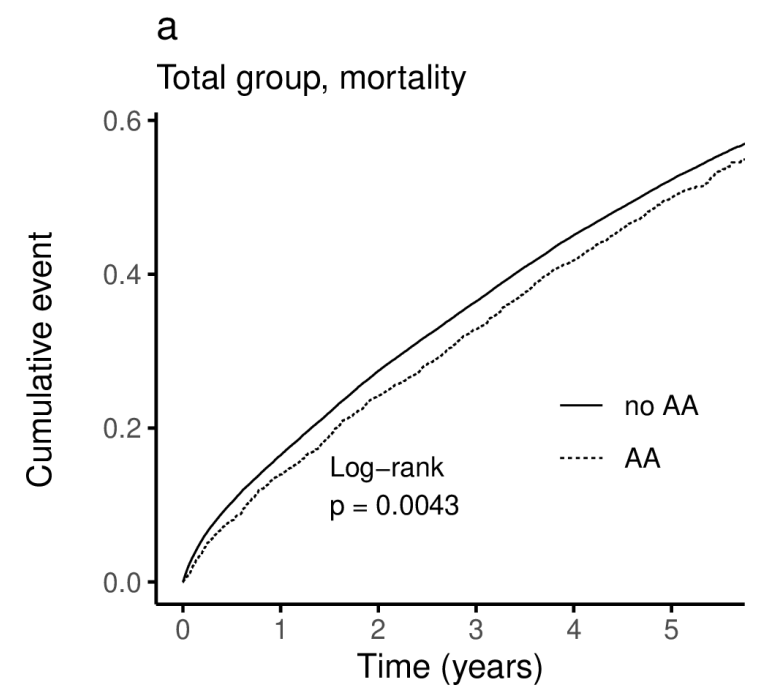

b

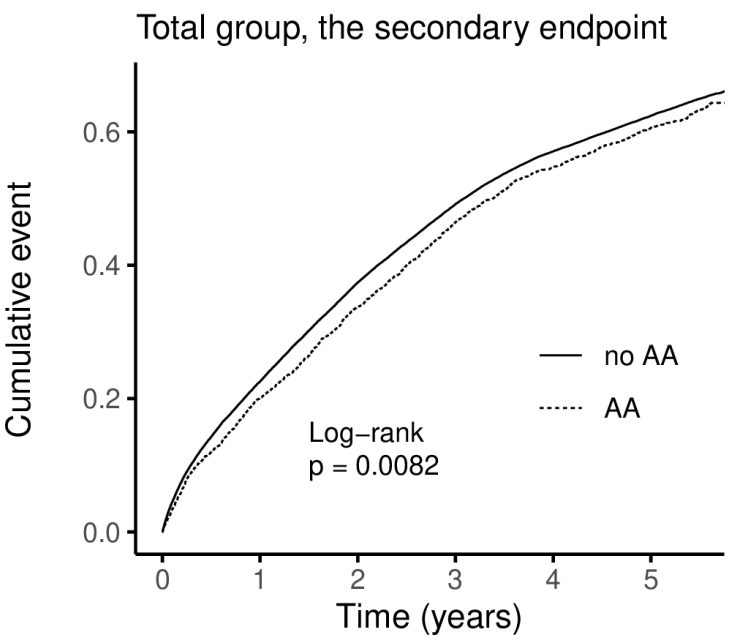

$\begin{array}{lllllll}\text { no } A A & 50881 & 42500 & 36925 & 32336 & 27952 & 22086\end{array}$

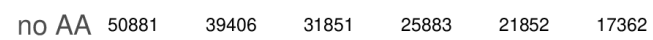

$\begin{array}{lllllll}\text { AA } & 2436 & 2096 & 1846 & 1635 & 1418 & 1094\end{array}$

$\begin{array}{lllllll}\text { AA } & 2436 & 1949 & 1613 & 1306 & 1106 & 860\end{array}$

$\mathrm{C}$

BB group, mortality

d
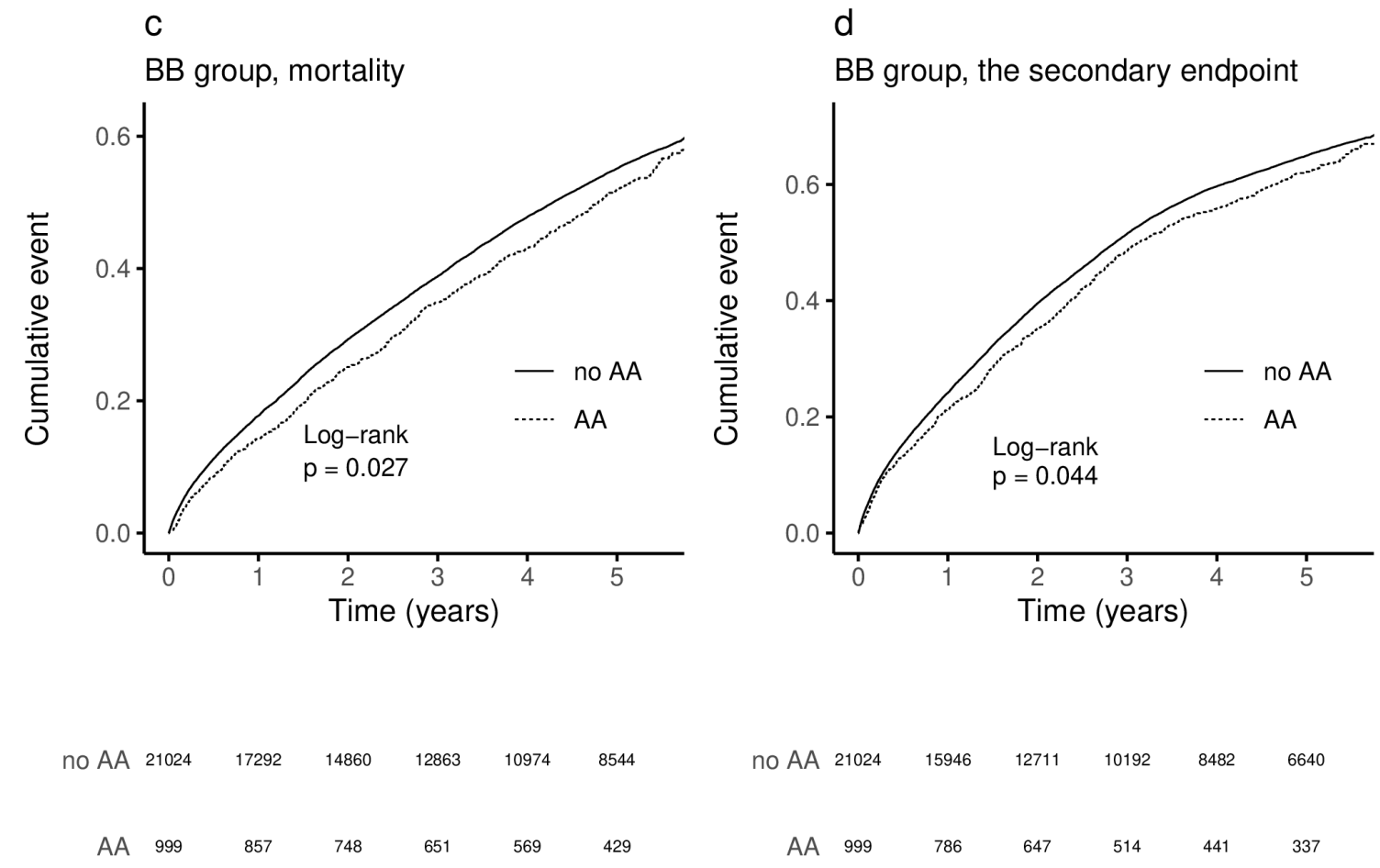

$\begin{array}{rrrrrrrrrrrrrr}\text { no AA } & 21024 & 17292 & 14860 & 12863 & 10974 & 8544 & \text { no AA } & 21024 & 15946 & 12711 & 10192 & 8482 & 6640 \\ \text { AA } & 999 & 857 & 748 & 651 & 569 & 429 & \text { AA } & 999 & 786 & 647 & 514 & 441 & 337\end{array}$

\section{Figure 2}

Primary (a) and secondary (b) endpoint in all patients, and beta-blocker (BB) treated patients respectively (c) and (d). AA - alpha-adrenolytics 


\begin{tabular}{|c|c|c|c|c|}
\hline \multirow{2}{*}{\multicolumn{5}{|c|}{$\begin{array}{l}\text { hererence } \\
0.82(0.78\end{array}$}} \\
\hline & & & & \\
\hline Sex & 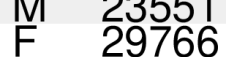 & & $\begin{array}{l}\text { Reterence } \\
0.68(0.66,0\end{array}$ & $<0.001$ \\
\hline $\begin{array}{l}\text { Age } \\
\text { Hospital_stay } \\
\text { RASI }\end{array}$ & $\begin{array}{r}53317 \\
53317 \\
\text { No } 13810\end{array}$ & & $\begin{array}{l}1.05(1.05,1.05 \\
1.04(1.03,1.04) \\
\text { Reference }\end{array}$ & $\begin{array}{l}<0.001 \\
<0.001\end{array}$ \\
\hline MRA & No 2996 & & , 0.85$)$ & $<0.001$ \\
\hline & Yes 23356 & & $, 1.10)$ & $<0.001$ \\
\hline Diuretics & $\begin{array}{l}\text { No } 231 \\
\text { Yoc } 205\end{array}$ & & $\begin{array}{l}\text { Rerere } \\
1201\end{array}$ & $<0001$ \\
\hline Digoxine & No 45920 & & Ref & \\
\hline CCB & No 43637 & & Refe & $<0.001$ \\
\hline Nitrates & $\begin{array}{l}\text { Yes } 96800 \\
\text { No } 47703\end{array}$ & & $\begin{array}{l}4,0.89) \\
e\end{array}$ & $<0.001$ \\
\hline Anticoagulants & $\begin{array}{l}\text { Yes } 56 \\
\text { No } 433\end{array}$ & & $1.01(0.98,1.05)$ & 0.5 \\
\hline Antidishos & Yes 9944 & & $0.78(0.76,0.81)$ & $<0.001$ \\
\hline Antidiabetics & $\begin{array}{l}\text { No } 39460 \\
\text { Yes } 13857\end{array}$ & & $.17,1.23)$ & $<0.001$ \\
\hline & $\begin{array}{l}\text { No } 32611 \\
\text { Yes } 20706\end{array}$ & & $0.85(0.83,0.87)$ & $<0.001$ \\
\hline
\end{tabular}

b

\begin{tabular}{|c|c|c|c|c|}
\hline \multirow{2}{*}{\multicolumn{5}{|c|}{ AA }} \\
\hline & & & & \\
\hline $\begin{array}{l}\text { Age } \\
\text { Hospital_stay } \\
\text { RASI }\end{array}$ & $\begin{array}{l}\mathrm{F} \quad 29766 \\
53317 \\
53317 \\
\mathrm{No} \\
13810\end{array}$ & E & $\begin{array}{l}0.73(0.71,0.75) \\
1.04(1.04,1.04) \\
1.03(1.03,1.04)\end{array}$ & $\begin{array}{l}<0.001 \\
<0.001 \\
<0.001\end{array}$ \\
\hline & Yes 39507 & & $0.85(0.83,0.87)$ & $<0.001$ \\
\hline IVIRA & Yes 23356 & & $1.04(1.02,1.07)$ & $<0.001$ \\
\hline Diuretics & $\begin{array}{l}\text { No } 23767 \\
\text { Yes } 29550\end{array}$ & & $\begin{array}{l}\text { ence } \\
1.14,1.19)\end{array}$ & $<0.001$ \\
\hline Digoxine & No 45920 & & $\begin{array}{l}\text { Referenc } \\
11611\end{array}$ & ○ $\cap 001$ \\
\hline CCB & No 43637 & & Refe & $<0.001$ \\
\hline Nitrates & $\begin{array}{l}\text { Yes } 46700 \\
\text { No } 47703\end{array}$ & & 0. & $<0.001$ \\
\hline Anticoagulants & $\begin{array}{l}\text { Yes } \\
\text { No } 433733\end{array}$ & & O. & 0.08 \\
\hline Antidiabetics & No 39460 & & Referenc & $<0.001$ \\
\hline Statins & No 3261 & & 21) & $<0.001$ \\
\hline
\end{tabular}

Figure 3

Cox analysis for primary (a) and secondary (b) endpoints in all patients. AA - alpha-adrenolytics; RASI renin angiotensin system inhibitors (converting enzyme inhibitor and/or angiotensin receptor blocker); MRA - aldosterone receptor antagonists; CCB - dihydropyridine calcium channel blockers 


\begin{tabular}{|c|c|c|c|c|}
\hline $\begin{array}{l}\text { Variable } \\
\text { AA }\end{array}$ & $\begin{array}{rr} & \mathbf{N} \\
\text { No } & 21024\end{array}$ & Hazard ratio & & p \\
\hline & Yes 999 & & $\begin{array}{l}\text { Rererence } \\
0.84(0.77,0.92)\end{array}$ & $<0.001$ \\
\hline Sex & 9992 & & Reference & \\
\hline & $\mathrm{F} \quad 12031$ & 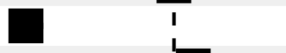 & $0.70(0.68,0.73)$ & $<0.001$ \\
\hline Age & $\begin{array}{r}22023 \\
8278\end{array}$ & & $1.05(1.04,1.05)$ & $<0.001$ \\
\hline & Yes 13645 & & $\begin{array}{l}\text { Rererence } \\
0.85(0.82,0.88)\end{array}$ & $<0001$ \\
\hline MRA & No 12820 & & Reference & \\
\hline & Yes 9203 & & $1.06(1.02,1.10)$ & 0.002 \\
\hline Carvedilol & 9001 & & Reference & \\
\hline Diqoxine & No 18581 & & $\begin{array}{l}1.27(1.23,1.32) \\
\text { Reference }\end{array}$ & $<0.001$ \\
\hline & 3442 & & $1.20(1.14,1.25)$ & $<0.001$ \\
\hline ССВ & No 18352 & & Reference & ? 001 \\
\hline Nitrates & No 19436 & & Reference & -0.001 \\
\hline Antidiahaticc & Yes & & $1.07(1.02,1.13)$ & 0.008 \\
\hline Amliarabelics & Yes 590 & & $118(1.14,123)$ & $<0.001$ \\
\hline Statins & No 132 & & Reference & \\
\hline & Yes 87 & & $0.84(0.81,0.87)$ & $<0.001$ \\
\hline
\end{tabular}

b

\begin{tabular}{|c|c|c|c|c|}
\hline Variable & $\mathrm{N}$ & Hazard ratio & & p \\
\hline & No 21024 & & Reference & \\
\hline Sex & $\begin{array}{l}\text { Yes } \\
\text { M } 9992\end{array}$ & & $\begin{array}{l}0.87(0.80,0.94) \\
\text { Reference }\end{array}$ & $<0.001$ \\
\hline & $\mathrm{F} \quad 12031$ & 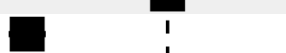 & $0.75(0.72,0.78)$ & $<0.001$ \\
\hline $\begin{array}{l}\text { Age } \\
\text { RASI }\end{array}$ & $\begin{array}{r}22023 \\
8378\end{array}$ & & $1.04(1.03,1.04)$ & $<0.001$ \\
\hline RASI & $\begin{array}{lr}\text { No } & 8378 \\
\text { Yes } & 13645\end{array}$ & & $0.85(0.82,0.88)$ & $<0.001$ \\
\hline MRA & No 12820 & & Reference & \\
\hline Carvedilol & 9001 & & $\begin{array}{l}1.03(1.00,1.07) \\
\text { Reference }\end{array}$ & 0.05 \\
\hline & 13022 & & $1.24(1.20,1.29)$ & $<0.001$ \\
\hline Digoxine & $\begin{array}{lr}\text { No } & 18581 \\
\text { Yes } & 3442\end{array}$ & & $\begin{array}{l}\text { Reterence } \\
1.16(1.11,1.21)\end{array}$ & $<0.001$ \\
\hline CCB & No 18352 & & Reference & \\
\hline Nitrates & No 19436 & & $\begin{array}{l}0.92(0.00,0.90) \\
\text { Reference }\end{array}$ & $<0.001$ \\
\hline & Yes & & $1.09(1.04,1.14)$ & $<0.001$ \\
\hline Antıdıabetıcs & 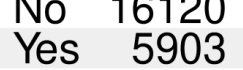 & & $\begin{array}{l}\text { Reterence } \\
1.16(1.12,1.20)\end{array}$ & $<0.001$ \\
\hline Statins & $\begin{array}{lr}\text { No } & 13240 \\
\text { Yes } & 8783\end{array}$ & & $\begin{array}{l}\text { Reference } \\
0.89(0.86,0.92)\end{array}$ & $<0.001$ \\
\hline
\end{tabular}

Figure 4

Cox analysis for primary (a) and secondary (b) endpoints in the subgroup treated with beta-blocker. AA alpha-adrenolytics; RASI - renin angiotensin system inhibitors (converting enzyme inhibitor and/or angiotensin receptor blocker); MRA - aldosterone receptor antagonists; CCB - dihydropyridine calcium channel blockers 


\section{Supplementary Files}

This is a list of supplementary files associated with this preprint. Click to download.

- Supplementarymaterial.pdf

- Dataset.csv 